\title{
Nanoparticle Enhanced Phase Change Material in Latent Heat Thermal Energy Storage System: An Experimental Study
}

\author{
Muath A. Alomair, Yazeed A. Alomair, Hussein A. Abdullah, Shohel Mahmud, Syeda Tasnim \\ School of Engineering, University of Guelph \\ 50 Stone Road East, Guelph, ON, N1G 2W1 Canada \\ stasnim@uoguelph.ca
}

\begin{abstract}
Latent heat thermal energy storage (LHTES) system uses a phase change material (PCM) to store or release thermal energy, thus reducing the overall consumption of energy in a system. But, the problem with the PCM is their low thermal conductivity that increases the melting and solidification time, which is not suitable for specific application areas, such as, battery thermal management, electronic cooling etc. To increase the thermal conductivity of PCM, different studies examine different approaches including extension of the heat transfer area using fins and honeycombs, thin metal strips, porous metals, copper chips, metal foam matrices, metal screens and spheres, carbon fiber brushes and chips, graphite matrices, microencapsulated PCM, multiple PCMs, carbon-based nanostructures graphene flakes, carbon nano-tubes, metallic nanoparticles, silver nano-wires, and bio-based composite PCM. The current study incorporates nanoparticle in PCM (nano-PCM) to increase the thermal conductivity of the PCM. Experimental studies are performed using Copper Oxide (50nm) and Aluminum Oxide (50nm) nanoparticles supplied by Sigma Aldrich and Rubitherm (RT-18) as base PCM, supplied by Rubitherm GmbH. The vertical cylindrical LHTES is composed of two concentric pipes; with the inner one carrying a heat transfer fluid at a constant temperature and the annular space containing a nano-PCM. The initial temperature of the nano- $\mathrm{PCM}$ is $5{ }^{\circ} \mathrm{C}$ while the temperature of the heat transfer fluid is $40{ }^{\circ} \mathrm{C}$. The experimental results show that using nano-PCM reduces the melting time when compared to base PCM, but enhanced melting is observed when Copper Oxide nanoparticle is used.
\end{abstract}

Keywords: Melting; Latent heat thermal energy storage; Phase change material; Nanoparticles; Thermal conductivity.

\section{Introduction}

Phase change materials (PCMs) are extensively used as thermal energy storage materials because of their capability of storing and releasing large amounts of thermal energy during the phase change melting and solidification [1]. Due to environmental concerns and rise of fossil fuels cost, PCMs are becoming increasingly vital for many engineering applications such as, battery thermal management, electronic cooling, buildings space heating and cooling. In the current study, a cylindrical geometry is selected as it is considered most promising for commercial heat exchangers, because of its high efficiency in a minimum volume [2]. The primary disadvantage of PCMs is that they have relatively low thermal conductivity, which reduces their melting and solidification rates [1-2]. Many studies investigated heat transfer enhancement of PCMs in cylindrical enclosures [3 to 13]. Table 1 represents a summary of experimental and/or numerical studies that investigate different PCMs incorporating nanoparticles.

Table 1: A summary of literature review.

\begin{tabular}{|c|c|c|c|c|c|c|}
\hline Authors & $\begin{array}{c}\text { Numerical/ } \\
\text { Experimental/ } \\
\text { Analytical }\end{array}$ & $\begin{array}{c}\text { Melting/ } \\
\text { Solidification }\end{array}$ & $\begin{array}{c}\text { PCM / Melting } \\
\text { Temperature }\end{array}$ & Nanoparticles & Purpose & Results \\
\hline Jourabian et al. [3] & Numerical & Melting & Water $/ 0^{\circ} \mathrm{C}$ & $\begin{array}{c}\text { Copper } / \\
2 \& 4 \mathrm{vol} \%\end{array}$ & $\begin{array}{c}\text { Enhancing heat transfer by } \\
\text { 2-D analytical analysis }\end{array}$ & $\begin{array}{c}\text { Nanofluid removes heat faster than } \\
\text { pure liquid }\end{array}$ \\
\hline $\begin{array}{c}\text { Dhaidan et al. [4] } \\
2013\end{array}$ & $\begin{array}{c}\text { Numerical \& } \\
\text { Experimental }\end{array}$ & Melting & $\begin{array}{c}\text { n-octadecane / } \\
28^{\circ} \mathrm{C}\end{array}$ & $\begin{array}{c}\text { Copper Oxide, 9nm } \\
/ 0,1,3 \& 5 \mathrm{wt} \%\end{array}$ & $\begin{array}{c}\text { Enhancing heat transfer by } \\
\text { adding different weight } \\
\text { fractions of nanoparticles }\end{array}$ & $\begin{array}{c}\text { More nanoparticles improve } \\
\text { charging time, heat transfer rate, and } \\
\text { thermal conductivity }\end{array}$ \\
\hline $\begin{array}{c}\text { Parsazadeh and } \\
\text { Duan [5] }\end{array}$ & $\begin{array}{c}\text { Numerical \& } \\
\text { Experimental }\end{array}$ & Melting & $\begin{array}{c}\text { Paraffin wax / } \\
53-57^{\circ} \mathrm{C}\end{array}$ & $\begin{array}{c}\text { Copper Oxide 10nm } \\
/ 0-7 \text { vol. } \%\end{array}$ & $\begin{array}{c}\text { Improving heat transfer by } \\
\text { adding nanoparticles in } \\
\text { HTF }\end{array}$ & $\begin{array}{c}\text { transfer rate between the HTF and } \\
\text { the PCM increases with adding } \\
\text { nanoparticles into the HTF }\end{array}$ \\
\hline
\end{tabular}




\begin{tabular}{|c|c|c|c|c|c|c|}
\hline Authors & $\begin{array}{l}\text { Numerical/ } \\
\text { Experimental/ } \\
\text { Analytical }\end{array}$ & $\begin{array}{l}\text { Melting/ } \\
\text { Solidification }\end{array}$ & $\begin{array}{l}\text { PCM / Melting } \\
\text { Temperature }\end{array}$ & Nanoparticles & Purpose & Results \\
\hline $\begin{array}{c}\text { Mahdi \& Nsofor } \\
{[6]}\end{array}$ & Numerical & Solidification & $\begin{array}{l}\text { Paraffin RT82 / } \\
76.85-84.85^{\circ} \mathrm{C}\end{array}$ & $\begin{array}{c}\text { Alumina / 3-8 } \\
\text { vol. } \%\end{array}$ & $\begin{array}{c}\text { Investigating Paraffin } \\
\text { RT82 PCM performance } \\
\text { by adding Aluminum } \\
\text { Oxide } \\
\end{array}$ & $\begin{array}{l}\text { Faster heat transfer rate with increase } \\
\text { in volume fraction of nanoparticles }\end{array}$ \\
\hline $\begin{array}{c}\text { Parameshwaran \& } \\
\text { Kalaiselvam [7] }\end{array}$ & $\begin{array}{l}\text { Numerical \& } \\
\text { Experimental }\end{array}$ & $\begin{array}{c}\text { Melting \& } \\
\text { Solidification }\end{array}$ & $\mathrm{PCM} / \times$ & $\begin{array}{c}\text { Silver (AgNP) / } 46 \\
\mathrm{~nm} \& 54 \mathrm{~nm} / 1 \\
\text { wt } \%\end{array}$ & $\begin{array}{c}\text { Enhancing heat transfer by } \\
\text { adding nanoparticles in } \\
\text { PCM }\end{array}$ & $\begin{array}{c}\text { The system achieves an on-peak } \\
\text { energy savings potential of } 58 \% \text { (per } \\
\text { day average) compared to } \\
\text { conventional air conditioning system }\end{array}$ \\
\hline Agyenim et al. [8] & $\begin{array}{l}\text { Numerical \& } \\
\text { Experimental }\end{array}$ & $\begin{array}{c}\text { Melting \& } \\
\text { Solidification }\end{array}$ & $\begin{array}{c}\text { Erythritol / } \\
117.7^{\circ} \mathrm{C}\end{array}$ & $x$ & $\begin{array}{c}\text { Enhancing heat transfer by } \\
\text { adding fins }\end{array}$ & $\begin{array}{c}\text { Heat transfer of finned tubes is } \\
\text { enhanced }\end{array}$ \\
\hline Hosseini et al. [9] & $\begin{array}{l}\text { Numerical \& } \\
\text { Experimental }\end{array}$ & Melting & Paraffin $/ 51^{\circ} \mathrm{C}$ & $x$ & $\begin{array}{c}\text { Investigating melting } \\
\text { process of PCM in a tube }\end{array}$ & $\begin{array}{l}37 \% \text { encampment with increasing } \\
\text { HTF to } 80^{\circ} \mathrm{C} \text { numerically }\end{array}$ \\
\hline $\operatorname{Trp}[10]$ & $\begin{array}{l}\text { Numerical \& } \\
\text { Experimental }\end{array}$ & $\begin{array}{l}\text { Melting \& } \\
\text { Solidification }\end{array}$ & $\begin{array}{c}\text { Rubitherm RT- } \\
30 / \\
27.55^{\circ} \mathrm{C}\end{array}$ & $x$ & $\begin{array}{l}\text { Investigating heat transfer } \\
\text { from HTF to PCM }\end{array}$ & $\begin{array}{c}\text { Thermal behaviour of melting and } \\
\text { solidification are identical } \\
\text { numerically \& experimentally }\end{array}$ \\
\hline Diaconu et al. [11] & Experimental & Solidification & $\begin{array}{c}\text { Rubitherm RT6 } \\
/ 6^{\circ} \mathrm{C}\end{array}$ & $x$ & $\begin{array}{c}\text { Investigating heat transfer } \\
\text { characteristics of PCM and } \\
\text { water }\end{array}$ & $\begin{array}{l}\text { Phase change period values of the } \\
\text { heat transfer coefficient of PCM was } \\
\text { significantly higher than water }\end{array}$ \\
\hline $\begin{array}{c}\text { Pandiyarajan et al. } \\
{[12]}\end{array}$ & Experimental & Melting & $\begin{array}{c}\text { Paraffin wax / } \\
58-60^{\circ} \mathrm{C}\end{array}$ & $x$ & $\begin{array}{l}\text { Investigating heat storage } \\
\text { in diesel engine exhaust } \\
\text { with a finned cylinder }\end{array}$ & $15 \%$ of system's heat is stored \\
\hline $\begin{array}{c}\text { Turnpenny et al. } \\
{[13]}\end{array}$ & $\begin{array}{l}\text { Analytical \& } \\
\text { Experimental }\end{array}$ & Melting & $\begin{array}{c}\text { Glauber's Salt / } \\
24.5-27^{\circ} \mathrm{C}\end{array}$ & $x$ & $\begin{array}{l}\text { Investigating heat transfer } \\
\text { and model behaviour }\end{array}$ & $\begin{array}{c}\text { With a temperature deference of } 5^{\circ} \mathrm{C}, \\
\text { the heat transfer rate was } 40 \mathrm{~W} \text { for a } \\
\text { melting } \\
\text { period of } 19 \mathrm{~h}\end{array}$ \\
\hline
\end{tabular}

The objective of the current study is to visualize transient melting when nano-PCM is used as a thermal energy storage medium instead of base PCM. This study will further improve our understanding of the fundamental of solid-liquid phase transition during melting dynamical behaviour, and a better characterization of the related heat transfer.

\section{Experimental Setup and Procedures}

An experimental setup is built to carry out series of experiments for visualization. The experimental setup consists of two cylindrical LHTES systems, temperature regulator, K-type thermocouples, camera, NI data acquisition system, and a computer. Fig. 1 shows the experimental setup with all the different components.

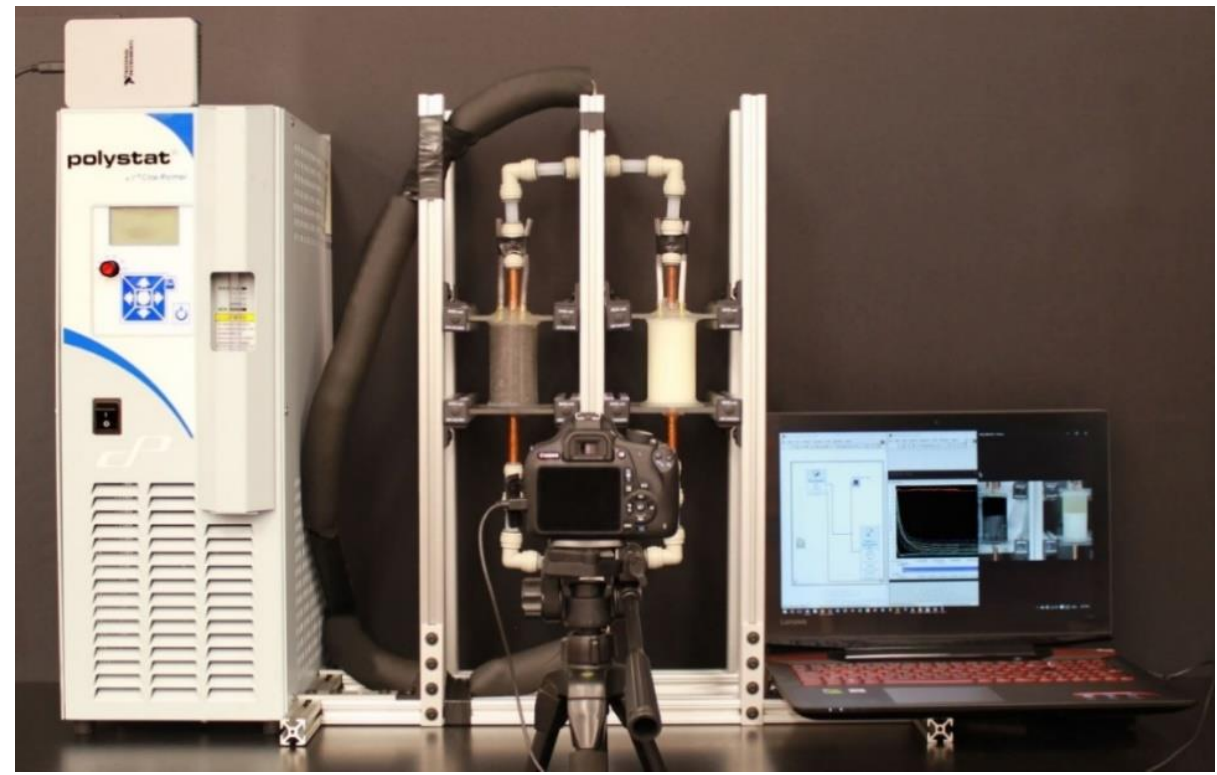

Fig. 1: Experimental setup showing Rubitherm and Copper Oxide nanoparticles on the left-hand side and Rubitherm and Aluminum Oxide nanoparticles on the right of the test stand. 
The experimental setup is built to carry out two experiments with nano-PCM at the same time for comparison of transient melting using two different nanoparticles. In the current study, we consider two nano-PCMs in two different cylindrical LHTES systems. The vertical cylindrical LHTES is composed of two concentric pipes; the copper pipe (inner one), carrying water as a heat transfer fluid at a constant temperature and the annular space containing a nano-PCM. The Plexiglas vertical cylinder has $4.45 \mathrm{~cm}$ internal diameter and $8.96 \mathrm{~cm}$ height. The water is continuously circulated by a built-in force/suction pump which has a maximum flow rate of $21 \mathrm{~L} / \mathrm{min}$. The water capacity is $2.8 \mathrm{~L}$. Also, the Polystat temperature regulator has a temperature range of $5-80^{\circ} \mathrm{C}$, and it maintains the temperature to $\pm 0.1^{\circ} \mathrm{C}$. The temperature regulator requires $115 \mathrm{~V}$ and $250 \mathrm{~W}$ input power. A high definition Canon camera "EOS Rebel T2i model" is used to capture the melting images periodically. The laptop monitor is used to extract and save the periodic images through a wire connected to the camera. For the experimental procedure, the initial temperature of nano-PCM in the LHTES is $5^{\circ} \mathrm{C}$. The temperature regulator heats the water to $40^{\circ} \mathrm{C}$. Then, it passes the heated water through the copper pipe in the centre of the cylindrical LHTES system. Meanwhile, the camera is capturing the melting process every 1 minute until the nano-PCM is completely melted. The captured images obtained from the experimental works are summarized and discussed in the results and discussion section. The detailed description of the experimental set up and procedure is also available in Muath et al. [14]. The mass fraction of Aluminum and Copper Oxide nanoparticles is 1\%. The preparation of nano-PCM is completed in 2 steps: in step (1), nano-PCMs are prepared by mixing the liquid RT-18 with Aluminum or Copper Oxide with required mass fraction in a magnetic stirrer for 24 hours. In step (2), the mixture of PCM and nanoparticles is sonicated for 30 minutes in a sonicator. The nano-PCM is poured into the cylindrical LHTES system through the vent using a pressure syringe in multiple steps to ensure no air is trapped inside the enclosure.

\section{Results and Discussion}

\subsection{Visualization of Melting Front}

Fig. 2 shows the images of melting of RT-18 when the temperature of water is $40^{\circ} \mathrm{C}$ and the initial temperature of solid phase RT- 18 is $5^{\circ} \mathrm{C}$. The overall images of Fig. 2 shows that solid PCM located in the upper layer melts first and the melting front moves downward with the cylindrical shape until the melting is completed.

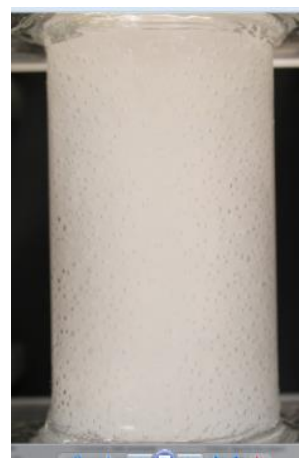

Time $=1 \mathrm{~min}$

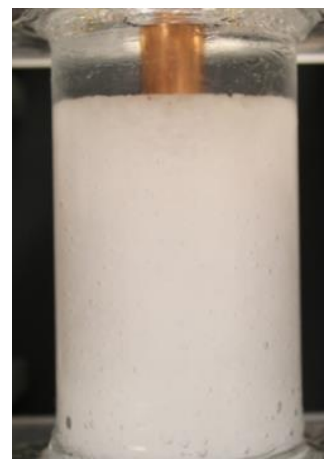

Time $=21 \mathrm{~min}$

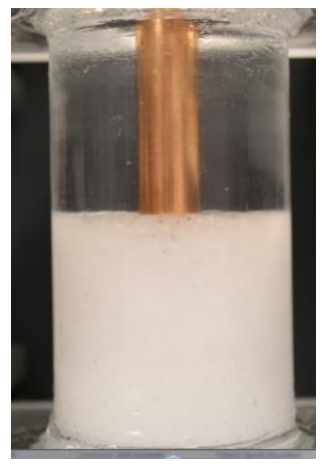

Time $=35 \mathrm{~min}$

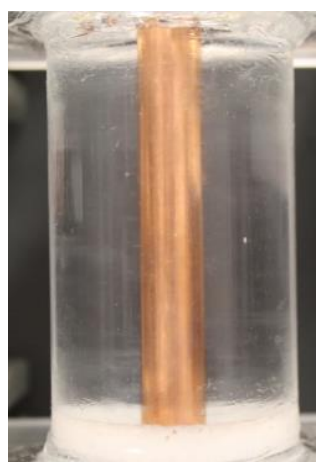

Time $=58 \mathrm{~min}$

Fig. 2: Transient images of melting of RT-18.

Fig. 3 shows the images of melting for the identical experimental conditions to that of Fig. 2 for two different cases at different times. In Fig. 3, the right-hand side of the test stand contains a mixture of Aluminum Oxide and RT-18 while the left-hand side contains a mixture of Copper Oxide and RT-18. Melting behaviour remains the same to that of base PCM, RT-18 in Fig. 2. The qualitative results show a faster melting in Fig. 3, i.e., for both nano-PCMs. For base PCM, i.e., RT18, 66 minutes is required for complete melting of solid PCM, while incorporating nanoparticles in PCM reduces the melting time to 58 minutes. But, a faster melting is observed while Copper Oxide nanoparticle is used compared to Aluminum Oxide nanoparticles. 


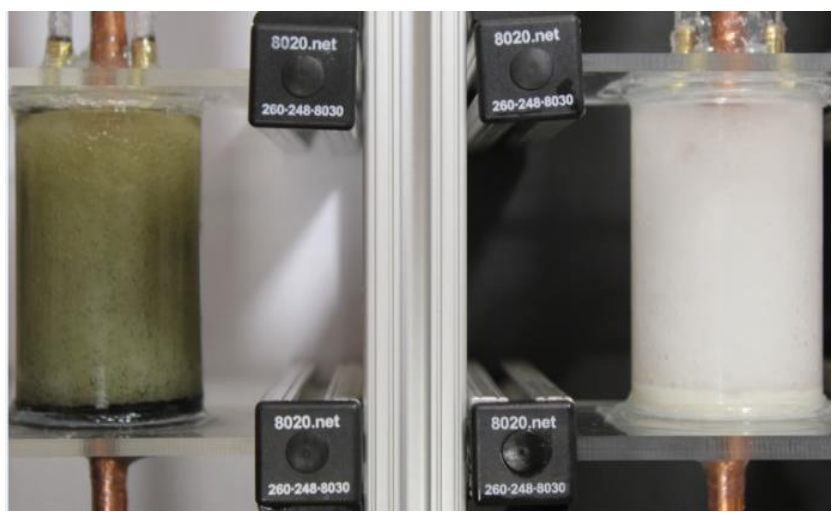

Time $=7 \mathrm{~min}$

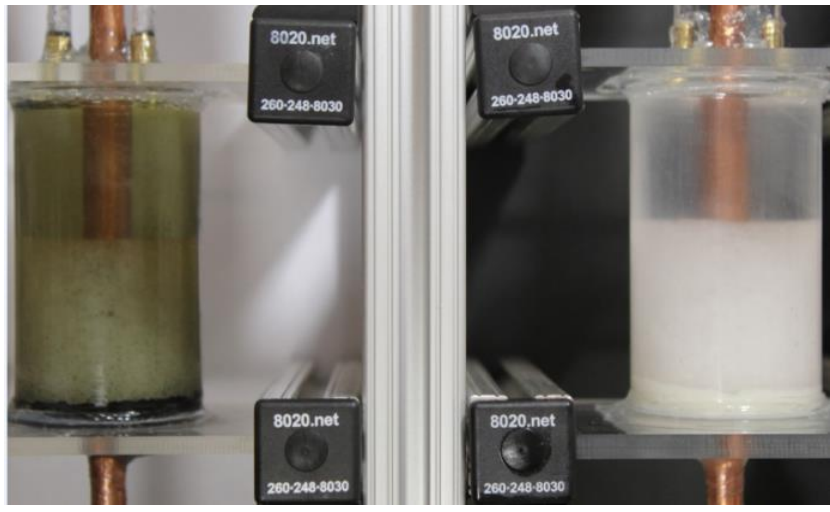

Time $=28 \mathrm{~min}$

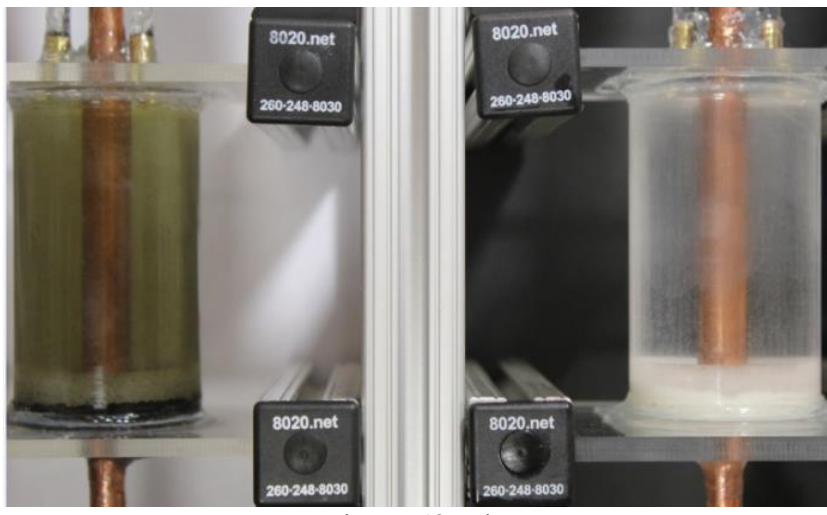

Time $=50 \mathrm{~min}$

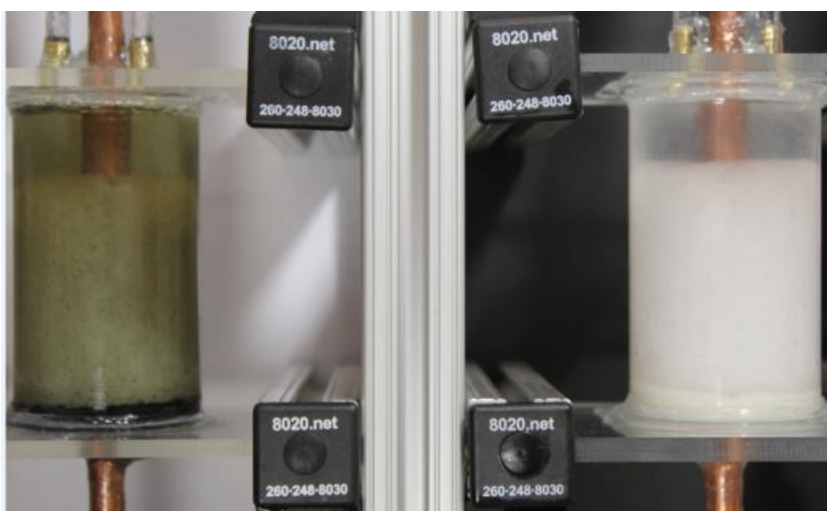

Time $=17 \mathrm{~min}$

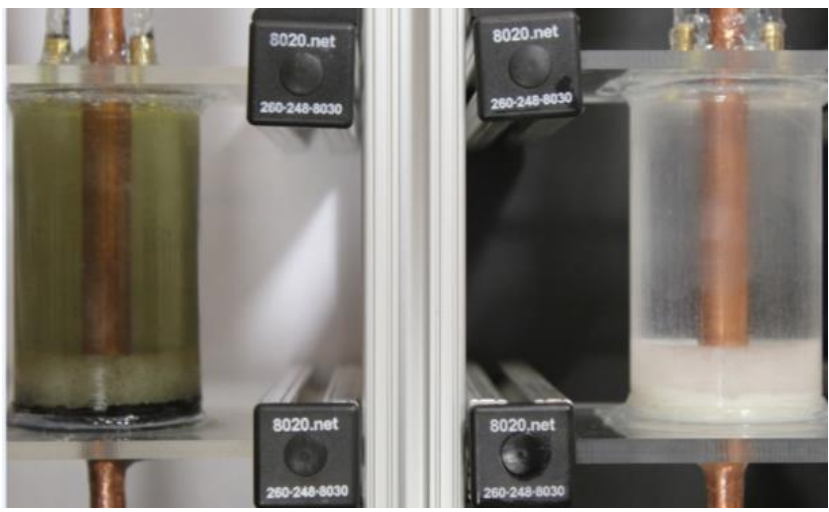

Time $=46 \mathrm{~min}$

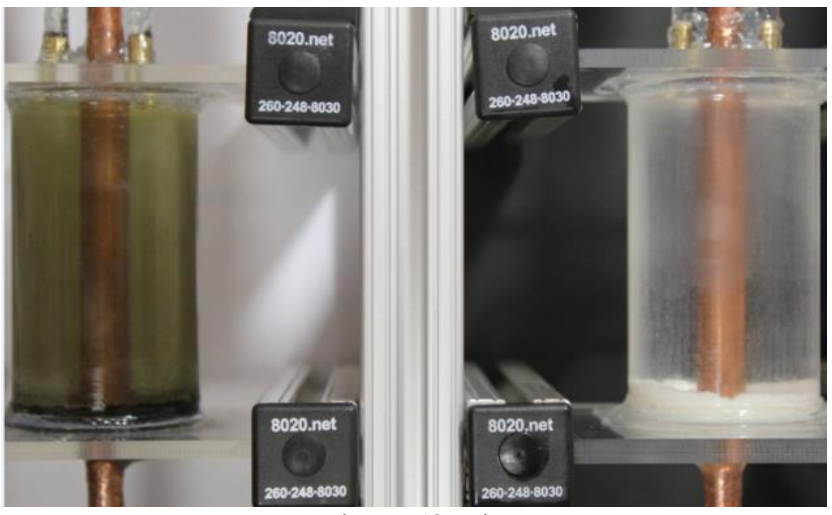

Time $=58 \mathrm{~min}$

Fig. 3: Visualization of transient melting; left hand side of the test stand contains RT-18 and Copper Oxide nanoparticles and on the right-hand side contains RT-18 and Aluminum Oxide nanoparticles.

\section{Conclusion}

The current study aims to qualitatively observe the transient melting of RT-18 and compare the melting process and melting time while Copper and Aluminum Oxide nanoparticles are mixed with RT-18. To achieve this goal, an experimental setup is built up for the visualization of melting and melt front location. The results show that melting behaviour remains the same for the base PCM and nano-PCMs, while a faster melting rate is observed for Copper Oxide nanoparticles than Aluminum Oxide. In future, different nanoparticles with different volume fractions will be incorporated along with porous medium to further enhance the heat transfer during phase change processes of PCMs. 


\section{References}

[1] H. Mehling and L. F. Cabeza, Heat and cold storage with PCM: An up to date introduction into basics and applications. Springer-Verlag, Berlin Heidelberg, 2008, pp. 11-52.

[2] A. A. Al-Abidi, S. B. Mat, K. Sopian, M. Y. Sulaiman, C. H. Lim and A. Th, "CFD applications for latent heat thermal energy storage: a review," Renew. Sust. Energy Reviews, vol. 20, pp. 353-363, 2013.

[3] M. Jourabian, M. Farhadi and A. A. R. Darzi, "Outward melting of ice enhanced by $\mathrm{Cu}$ nanoparticles inside cylindrical horizontal annulus: Lattice Boltzmann approach,” Appl.Math. Modelling, vol. 37, pp. 8813-8825, 2013.

[4] N. S. Dhaidan, J. M. Khodadadi, T. A. Al-Hattab and S. M. Al-Mashat, "Experimental and numerical study of constrained melting of n-octadecane with $\mathrm{CuO}$ nanoparticle dispersions in a horizontal cylindrical capsule subjected to a constant heat flux," Int. J. Heat Mass Transfer, vol. 67, pp. 523-534, 2013.

[5] M. Parsazadeh and X. Duan, "Numerical and statistical study on melting of nanoparticle enhanced phase change material in a shell-and-tube thermal energy storage system," Appl. Therm. Eng., vol. 111, pp. 950-960, 2017.

[6] J. M. Mahdi and E. C. Nsofor, "Solidification of a PCM with nanoparticles in triplex-tube thermal energy storage system," Appl. Ther. Eng., vol. 108, pp. 596-604, 2016.

[7] R. Parameshwaran and S. Kalaiselvam, "Energy conservative air conditioning system using silver nano-based PCM thermal storage for modern buildings," Energy Buildings, vol. 69, pp. 202-212, 2014.

[8] F. Agyenim, P. Eames and M. Smyth, "A comparison of heat transfer enhancement in a medium temperature thermal energy storage heat exchanger using fins," Sol. Energy, vol. 83, pp. 1509-1520, 2009.

[9] M. J. Hosseini, A. A. Ranjbar, K. Sedighi and M. Rahimi, "A combined experimental and computational study on the melting behavior of a medium temperature phase change storage material inside shell and tube heat exchanger," Int. Comm. Heat Mass Transfer, vol. 39, pp. 1416-1424, 2012.

[10] A. Trp, "An experimental and numerical investigation of heat transfer during technical grade paraffin melting and solidification in a shell-and-tube latent thermal energy storage unit," Sol. Energy, vol. 79, pp. 648-660, 2005.

[11] B. M. Diaconu, S. Varga, and A. C. Oliveira, "Experimental study of natural convection heat transfer in a microencapsulated phase change material slurry," Energy, vol. 35, pp. 2688-269, 2010.

[12] V. Pandiyarajan, M. Chinna Pandian, E. Malan, R. Velraj and R.V. Seeniraj, "Experimental investigation on heat recovery from diesel engine exhaust using finned shell and tube heat exchanger and thermal storage system," App. Energy, vol. 88, pp. 77-87, 2011.

[13] J. R. Turnpenny, D. W. Etheridge and D. A. Reay, "Novel ventilation cooling system for reducing air conditioning in buildings. Part I: testing and theoretical modelling," Appl. Ther. Eng., vol. 20, pp. 1019-1037, 2000.

[14] M. Alomair, Y. Alomair, H. A. Abdullah, S. Mahmud, S. H. Tasnim, "Experimental investigation of cylindrical thermal energy storage system using Bio-based phase change materials," in Proceedings of International Conference of Energy Harvesting, Storage, and Transfer, Toronto, Canada, 2017. 